\title{
Hypothesis \\ Potential of Farnesyl Transferase Inhibitors in Combination Regimens in Squamous Cell Carcinomas
}

\author{
Linda Kessler, Shivani Malik, Mollie Leoni and Francis Burrows * \\ Kura Oncology, Inc., San Diego, CA 92130, USA; linda@kuraoncology.com (L.K.); \\ smalik@kuraoncology.com (S.M.); mleoni@kuraoncology.com (M.L.) \\ * Correspondence: francis@kuraoncology.com; Tel.: +1-858-500-8854
}

check for updates

Citation: Kessler, L.; Malik, S.; Leoni, M.; Burrows, F. Potential of Farnesyl Transferase Inhibitors in Combination Regimens in Squamous Cell Carcinomas. Cancers 2021, 13, 5310 . https://doi.org/10.3390/cancers 13215310

Academic Editor: Charbel Darido

Received: 28 September 2021

Accepted: 19 October 2021

Published: 22 October 2021

Publisher's Note: MDPI stays neutral with regard to jurisdictional claims in published maps and institutional affiliations.

Copyright: (c) 2021 by the authors. Licensee MDPI, Basel, Switzerland. This article is an open access article distributed under the terms and conditions of the Creative Commons Attribution (CC BY) license (https:// creativecommons.org/licenses/by/ $4.0 /)$.
Simple Summary: Current therapies for recurrent and metastatic squamous cell carcinomas (SCCs) are associated with poor patient outcomes, and options for later lines of treatment are very limited. In cases where single-agent therapy may be insufficient to eradicate the tumor, thus allowing outgrowth of resistant cells, a well-chosen combination of therapeutic agents may enable improved outcomes. Tipifarnib, a farnesyl transferase inhibitor, is a small molecule drug candidate that has demonstrated promising clinical activity in HRAS-mutant head and neck squamous cell carcinoma (HNSCC). New molecular analyses suggest that HRAS may also be important in some HNSCC cases where it is not mutated, which might allow tipifarnib to be active in a broader population of HNSCC patients when used in combination with other agents such as cisplatin, cetuximab, or alpelisib. Other non-HRAS oncoproteins that can also be blocked by tipifarnib may offer alternative approaches to combination regimens for SCCs.

Abstract: Current therapies for recurrent and metastatic SCC are associated with poor outcomes, and options for later lines of treatment are limited. Insights into potential therapeutic targets, as well as mechanisms of resistance to available therapies, have begun to be elucidated, creating the basis for exploration of combination approaches to drive better patient outcomes. Tipifarnib, a farnesyl transferase inhibitor (FTI), is a small molecule drug that has demonstrated encouraging clinical activity in a genetically-defined subset of head and neck squamous cell carcinoma (HNSCC)-specifically, tumors that express a mutation in the HRAS protooncogene. More recently, bioinformatic analyses and results from patient-derived xenograft modeling indicate that HRAS pathway dependency may extend to a broader subpopulation of SCCs beyond HRAS mutants in the context of combination with agents such as cisplatin, cetuximab, or alpelisib. In addition, tipifarnib can also inactivate additional farnesylated proteins implicated in resistance to approved therapies, including immunotherapies, through a variety of distinct mechanisms, suggesting that tipifarnib could serve as an anchor for combination regimens in SCCs and other tumor types.

Keywords: HNSCC; farnesyl transferase; tipifarnib; combination regimen

\section{Tipifarnib in HRAS-Mutant HNSCC-History, Preclinical Validation, and Clinical Development}

The RAS family is a group of low molecular weight guanosine triphosphate (GTP)binding proteins localized to the cell membrane that play a pivotal role in the transduction of cell growth-stimulating signals. Well-established effectors of RAS are the protein kinase RAF and the lipid kinase PI3-kinase (PI3K). Following recruitment by RAS to the plasma membrane and activation by phosphorylation, RAF induces a phosphorylation cascade that drives the transcription of genes associated with cell proliferation [1]. PI3K activation leads to increased cell motility, invasiveness, and suppression of apoptosis [2,3]. RAS-driven downstream effector pathways also regulate the cell cycle and integrin signaling $[4,5]$.

Approximately $30 \%$ of human tumors express a mutation in one of three $R A S$ protooncogenes (KRAS, NRAS, and HRAS) encoding four RAS proteins (KRAS4A, KRAS4B, 
NRAS, and HRAS) [6]. The frequency of RAS mutation and the dominant isoform vary depending on the tissue and tumor type [7]. The majority of these mutations are localized to codons 12,13, or 61 and defined as "activating mutations" because they encode RAS proteins with suppressed GTPase activity that allows RAS to remain in the GTP-bound active state $[8,9]$. The critical role of RAS in oncogenic transformation was characterized by expression of dominant-negative forms of RAS and homologous recombination to disrupt mutated, active $R A S$ genes in various human cancer cell lines [10,11].

RAS isoforms must associate with the inner surface of the plasma membrane to transduce extracellular signals. To become active, RAS undergoes several post-translational modifications. The first step is the farnesylation of the cysteine in the CAAX box at the $\mathrm{C}$-terminal end (where $\mathrm{C}$ represents cysteine, $\mathrm{A}$ represents an aliphatic amino acid, and $X$ represents any amino acid) [6]. The enzyme farnesyltransferase (FTase) recognizes the CAAX motif and transfers a 15-carbon farnesyl isoprenoid from farnesyl diphosphate to the cysteine residue. The AAX amino acids subsequently are cleaved by RAS-converting enzyme I, and the farnesylated cysteine is carboxymethylated by isoprenylcysteine carboxyl methyltransferase [12]. Further palmitoylation (KRAS4A, NRAS, and HRAS or the presence of a polybasic domain (KRAS4B) leads to anchoring of the protein in the plasma membrane [13].

With the elucidation of this RAS post-translational modification pathway in the late 1980s, FTase became a viable pharmacological target to affect RAS function in cancer. Preliminary strategies were directed towards CAAX tetrapeptide inhibitors, which were competitive with the protein substrate [14]. However, such tetrapeptides were not efficiently taken up into cells, and the drug discovery efforts shifted toward more stable, peptidomimetic inhibitors [15-18]. Small molecule inhibitors were identified through high-throughput screening efforts and aided by crystallographic structures [19]. One such drug candidate, which later advanced into clinical evaluation, was R115777, also known as tipifarnib, a heterocyclic non-peptidomimetic that inhibits the FTase prenylation of KRAS in vitro with an $\mathrm{IC}_{50}$ of $7.9 \mathrm{nM}$ [20].

Tipifarnib was the first FTI to enter clinical development in 1997, and its safety and efficacy have been assessed in more than 70 clinical studies [21-25]. Observations that mutations within KRAS are most common in lung, colorectal, and pancreatic tumors; NRAS mutations typically observed in human myeloid cancers; and HRAS mutations found in bladder, thyroid, and head and neck tumors [8] helped guide the clinical development program. However, Phase 3 trials in non-enriched patient populations resulted in no significant antitumor effect in patients with advanced colorectal cancer [26]. In addition, no significant increase in response rate was observed in patients with pancreatic carcinoma when tipifarnib was combined with gemcitabine [27]. Overall, tipifarnib failed to achieve clinically meaningful improvements in two solid tumors known to highly express mutations in KRAS. Subsequently, it was discovered that certain farnesylated proteins-including KRAS and NRAS - can be rescued from membrane displacement in the presence of FTIs by an alternative prenylation by the enzyme geranylgeranyltransferase (GGTase) [28,29]. Conversely, the third family member, HRAS, is not a GGTase substrate, and therefore its membrane localization and cellular function are diminished by FTIs [29]. Thus, it was hypothesized that using tipifarnib to target enriched patient populations of tumors harboring HRAS mutations via a classical precision medicine approach might yield more favorable clinical outcomes.

Despite being comparatively less frequent than those of KRAS and NRAS, mutations in HRAS are highly expressed in follicular thyroid cell-derived and in medullary thyroid carcinomas, as well as in head and neck and bladder cancers [30-34]. In a dedifferentiated thyroid cancer model, Untch et al. demonstrated that mice harboring flox-and-replace HRAS $^{\mathrm{G} 12 \mathrm{~V}}$ and floxed p53 alleles developed aggressive tumors and 50\% mortality after 40 weeks [35]. Treatment of these mice with tipifarnib significantly improved survival and reduced tumor volume relative to vehicle-treated controls at 14 days. However, a subset of mice presented persistent, albeit diminished, tumor growth, occurring despite 
appropriate HRAS defarnesylation, suggesting an adaptive response to FTI treatment. To confirm this hypothesis, the investigators treated human and murine HRAS mutant cell lines with tipifarnib and observed increased GTP loading of wild-type KRAS and NRAS, a mechanism by which the efficacy of blunting oncogenic HRAS signaling could be circumvented. The authors further demonstrated that prolonged treatment of HRAS mutant tumors with tipifarnib elicited the emergence of nonsense mutations in Nf1, which encodes a GTPase-activating protein that is a negative regulator of RAS. Notably, loss of function mutations in Nf1 have also been shown to confer resistance to other therapies for melanoma and lung cancer [36-38]. In addition to the Nf1 loss, an activating mutation was found in Gnas, a complex locus whose most well-characterized transcript is the stimulatory G-protein alpha subunit $\left(G_{\alpha s}\right)$. Similar findings have been described in the resistance to RAF inhibitors in melanoma cells, indicating that this mechanism may be common in cells that are dependent on cAMP for differentiated function [39]. Collectively, these adaptations to HRAS inhibition may limit the effectiveness of therapies for certain patients with HRAS mutant malignancies, although other concurrent oncogenomic abnormalities may also impact the response.

More recently, the efficacy of tipifarnib was examined in a series of cell- and patientderived xenograft models of head and neck squamous cell carcinoma (HNSCC) [40]. Genomic analyses have revealed that HRAS mutations occur in 6\% of HNSCC at initial diagnosis [41] and in 15\% of patients during acquisition of resistance to cetuximab [42], and HRAS mutations have been demonstrated to correlate with reduced response of HNSCC patients to cetuximab treatment [43]. Gilardi et al. reported that both tipifarnib and $H R A S$ knockdown significantly reduced the growth of HRAS mutated cell lines with no effects observed in HRAS wild-type cells. The investigators also demonstrated that tipifarnib induced selective anti-tumor activity, with HRAS wild-type tumors growing progressively on tipifarnib treatment but $H R A S$ mutant tumors being highly sensitive to tipifarnib when compared to control groups. In addition, tipifarnib significantly reduced angiogenesis, as shown previously [44-46], and inhibited cell cycle progression while inducing squamous cell differentiation. Indeed, the anti-tumor activity of tipifarnib shown by Gilardi and colleagues in these HNSCC HRAS mutant models was equivalent to or exceeded that reported with a combination of MAPK and PI3K inhibitors in a HRAS mutant lung cancer model [47]. Collectively, these findings highlight mutant HRAS as a targetable oncogene that can be inhibited by tipifarnib, resulting in either consistent stasis or tumor regression in vivo in multiple preclinical models.

Despite these promising results, the clinical efficacy of tipifarnib during its initial evaluation in the late 1990s and early 2000s was limited and response rates were insufficient to support registrational trials. However, since its reintroduction to the clinic in 2015, findings from several trials have supported mutant HRAS as a target for the treatment of a subset of patients with HNSCC. Most recently, Ho et al. reported data from a Phase 2 clinical trial (KO-TIP-001, NCT02383927) investigating the efficacy of tipifarnib in second line and beyond recurrent and/or metastatic (R/M) head and neck squamous cell carcinomas, among others [48]. Patients received a starting dose of tipifarnib of either 600 or $900 \mathrm{mg}$ administered orally twice daily on days 1-7 and 15-21 of 28-day treatment cycles until progression of disease or unacceptable toxicity. At the time of data analysis, 21 HNSCC patients with HRAS mutations with a variant allele frequency (VAF) of at least $20 \%$ had been treated with tipifarnib, of whom 18 were efficacy evaluable. The objective response rate among these evaluable patients was 50\%; those patients that did not have an objective response did obtain a best overall response of stable disease. Progression-free survival on tipifarnib was 5.9 months versus 3.6 months on the patients' most recent prior therapy. Safety was evaluated in all 30 treated HNSCC patients, regardless of VAF. The most frequently observed treatment-emergent adverse events (TEAEs) of any grade observed in $>10 \%$ of patients were hematological-related events (anemia, neutropenia, leukopenia, lymphopenia) and gastrointestinal disturbances (nausea). Three patients experienced TEAEs leading to tipifarnib discontinuation. All three events were not related to tipifarnib 
and possibly related to disease. Based on this encouraging clinical activity, an international, multi-center, open-label, single-arm, pivotal study of tipifarnib after failure of platinumbased therapy in recurrent or metastatic HNSCC with HRAS mutations, AIM-HN, is under way (NCT03719690). Furthermore, encouraging results in urothelial carcinoma and salivary gland tumors were also reported. Twenty-four percent of HRAS mutant metastatic urothelial carcinoma patients treated with tipifarnib experienced an objective response. In addition, of 13 patients with recurrent/metastatic salivary gland tumors (SGT) treated with tipifarnib, one experienced an objective response and an additional seven patients had stable disease as best response.

The recent completion of The Cancer Genome Atlas (TCGA) [41] has enabled the identification of patient populations harboring HRAS mutations that may benefit from tipifarnib therapy. Gilardi et al. performed a detailed analysis of genomic information in the TCGA database focused on revealing HRAS expression levels and mutational status in an array of cancer types [40]. The study showed that relatively few cancers harbor HRAS mutations, particularly thyroid cancer, pheochromocytoma and paraganglioma, and HNSCC, with HNSCC expressing the highest levels of HRAS transcripts. In agreement with previous findings, HRAS mutations are characterized, in most cases, by coincident loss-of-function mutations in caspase- 8 and by the absence of TP53 mutations. Moreover, HRAS mutant HNSCC cases are of low overall mutational burden and respond poorly to standard-of-care immuno-oncology therapies [41]. In summary, preclinical murine studies, in-depth oncogenic analyses, and ongoing clinical investigation in patients with mutant HRAS tumors may support tipifarnib as a novel precision therapeutic approach for HNSCC and other cancers.

\section{HRAS Dependency: Role of Unmutated HRAS in Progression and Chemoresistance in HNSCC}

Driver oncoproteins are commonly hyperactive forms of signaling molecules that regulate cellular proliferation and survival. This hyperactivity may be achieved by mutation leading to constitutive activation and/or by overexpression of the wild-type protein due to fusion with a highly expressed gene, genetic amplification or transcriptional dysregulation. Given that activating point mutations render the protein activity independent of upstream signaling, it is not surprising that mutations of a given tumor driver pack a greater oncogenic punch than either amplification or overexpression of the wild-type form. However, the protein need not be mutated to represent a valuable therapeutic target. Indeed, increasing preclinical and clinical data suggest that targeting wild-type oncoproteins has potential therapeutic value in the era of personalized medicine, particularly in the context of the combination regimens that are increasingly becoming the standard of care in cancer therapy [49].

Oncogene amplification and overexpression are common phenomena in solid tumors, particularly in SCCs. For example, KRAS is mutated in approximately $30 \%$ of cases of lung adenocarcinoma (ADC) in TCGA's PanCancer Atlas but amplified at a rate of only around $5 \%$; in lung SCC, the relative frequencies are reversed (1\% vs. $4 \%$ ). Similarly, EGFR is mutated in twice as many lung ADCs as it is amplified, compared to a threefold excess of amplification vs. mutation in LSCC, where frequencies of high polysomy and amplification may be up to $40 \%$ [50]. EGFR is very rarely mutated in HNSCC but is amplified 10-30\% of cases [51] and overexpressed at high frequency [52]. Perhaps the most compelling evidence for the importance of unmutated oncogenic driver proteins in SCCs is the approval and widespread use of the chimeric anti-EGFR antibody cetuximab as a standard of care treatment for HNSCC [53,54]. EGFR and MET are examples of receptor tyrosine kinases (RTK) that can become hyperactive through receptor clustering when overexpressed in HNSCC, but non-RTK oncogenes can also drive HNSCC, including PIK3CA, which is mutated and amplified at a higher prevalence, around 35\%, in HNSCC [55], and the oncogenic chloride channel ANO1/TMEM16, a core element of the 11q13 amplicon, is found in a quarter of HNSCCs and more than half of ESCCs [56,57]. 
Despite-or perhaps because of - the high prevalence of EGFR amplification and overexpression in HNSCC, several clinical studies failed to demonstrate enhanced sensitivity to cetuximab in amplified or overexpressing populations $[49,58]$. Therefore, although cetuximab is the first and the only FDA-approved targeted therapy in HNSCC to date, the prescribing information makes no reference to EGFR. The picture is less clear in other SCCs: preclinical studies showed superior activity of cetuximab in EGFR-amplified and overexpressing esophageal SCC (ESCC) xenografts [59], and EGFR-amplified and overexpressing lung SCC patients responded better to gefitinib [49] and cetuximab and chemotherapy $[54,60,61]$ than their EGFR ${ }^{\text {low }}$ counterparts. The FLEX trial compared chemotherapy (cisplatin and vinorelbine) with and without cetuximab in a cohort of first-line NSCLC patients, 35\% of whom were SCC [61]. Addition of cetuximab to the regimen resulted in a $38 \%$ reduction in risk of death and a 2.3-month net increase in median survival among those with EGFR overexpression with no difference in overall survival (OS) among those with low EGFR expression [61]; but in a similar trial with a different cocktail of chemotherapeutics (paclitaxel and carboplatin), outcomes were not associated with EGFR mutation, increase in EGFR gene copy number, or EGFR protein [62].

To begin exploring the therapeutic potential of HRAS inhibition via farnesyltransferase inhibition beyond the HRAS mutant fraction of HNSCC, we reasoned that the biology of tumors driven by hyperactivity of wild-type oncoproteins is likely to resemble that of their corresponding mutant counterparts more than that of tumors with unrelated driver pathways. Intriguingly, several groups have reported that HRAS-mutant SCCs co-cluster in unbiased genomic and epigenomic profiling analyses. Indeed, genomic clustering suggests that HRAS mutations define a unique subset of HNSCC, characterized in most cases by coincident loss of function mutations in caspase 8 and enrichment for absence (near-mutual exclusivity) of TP53 mutations $[40,55,63]$. Furthermore, a recent systematic analysis of TCGA SCC cohorts by Campbell and colleagues reported that HRAS-mutant HNSCCs also cluster on the basis of copy number variations (CNVs, i.e. chromosomal alterations) and methylation pattern [64]. Closer inspection of TCGA PanCancer Atlas cohorts revealed that, although amplification at the HRAS locus is surprisingly rare, SCCs express significantly higher levels of HRAS than adenocarcinomas, and HRAS mRNA is overexpressed in around $30 \%, 25 \%$, and $10 \%$ of cases of HNSCC, UC, and LSCC, respectively (Figure 1). The large majority of HRAS mutants are also found in the overexpressing population. Interestingly, the methylation cluster described in Campbell et al. is also significantly enriched for HRAS-overexpressing HNSCC cases, suggesting that HRAS expression levels could be used as a biomarker to explore the potential role of the wild-type form of the oncoprotein in HNSCC progression and drug resistance.

We tested tipifarnib (80 mg/kg, BID) as a single agent in a panel of around $20 \mathrm{HRAS}$ mutant and wild-type HNSCC patient-derived xenograft (PDX) models with mixed results. As reported previously [40], tipifarnib was highly active in the HRAS mutant setting and displayed weak activity in the majority of $H R A S$ wild-type models, but we observed unexpectedly robust inhibition of tumor growth in a minority of $H R A S$ wild-type cases, all of which expressed high levels of the HRAS gene (Figure 2). These hints of activity, while encouraging, were sporadic and variable in nature and did not extend to tumor regression, indicating that these tumors could tolerate HRAS depletion in isolation, but might also be rendered hypersensitive to other stressors. 


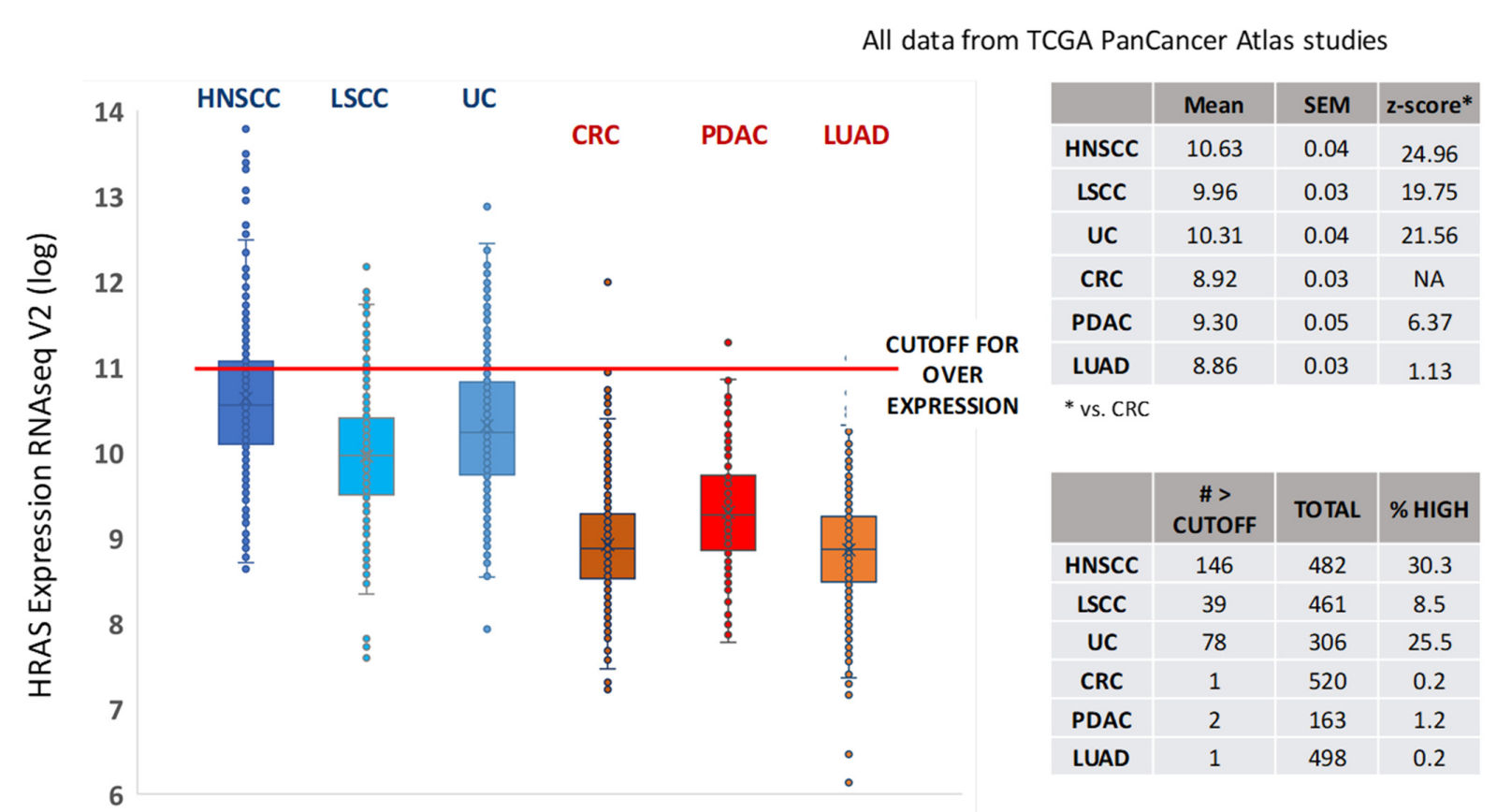

Figure 1. HRAS is overexpressed in squamous cell carcinomas. Data from TCGA PanCancer Atlas accessed at http: / / www.cbioportal.org/ (accessed on: 9 November 2020. Comparison of HRAS mRNA expression between the major adenocarcinomas, colorectal (CRC), pancreatic (PDAC), and lung (LUAD), and squamous cell carcinomas of the head and neck (HNSCC), lung (LSCC), and urothelium (UC). * vs. CRC.

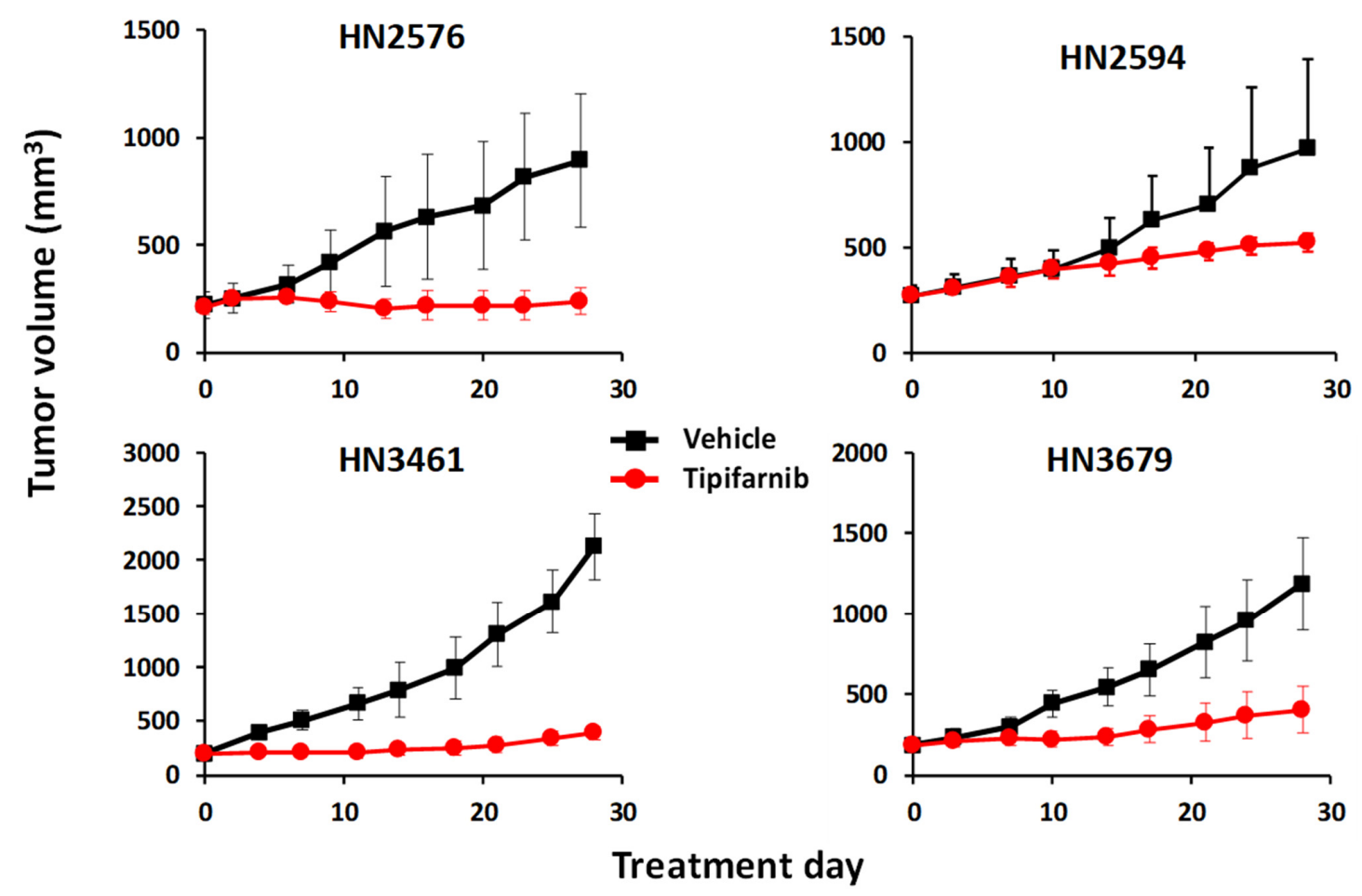

Figure 2. Some HRAS-overexpressing HNSCC PDX models are sensitive to tipifarnib. BALB/c nu/nu or SCID mice were inoculated subcutaneously with 2-3 mm tumor fragments, the PDX were allowed to establish to $250-350 \mathrm{~mm}^{3}$, the animals were randomized into groups of three and treated orally BID with vehicle or tipifarnib $(60 \mathrm{mg} / \mathrm{kg}$ for SCID, $80 \mathrm{mg} / \mathrm{kg}$ for $\mathrm{nu} / \mathrm{nu}$ ) for 25-30 days. Tumor volumes were measured twice weekly in two dimensions using a caliper, and the volume was expressed in mm3 using the formula: $\mathrm{V}=(\mathrm{L} \times \mathrm{W} \times \mathrm{W}) / 2$, where $\mathrm{V}$ is tumor volume, $\mathrm{L}$ is tumor length (the longest tumor dimension), and $\mathrm{W}$ is tumor width (the longest tumor dimension perpendicular to $\mathrm{L}$ ). 
With the notable exception of Herceptin and other HER2 antagonists, few drugs directed against non-mutated oncoprotein targets have proven effective as single agents [43], but it is more likely that clinically-actionable dependencies on overexpressed wild-type drivers will emerge in the context of synthetic lethal interactions with other therapies. Indeed, cetuximab demonstrated enhanced activity in EGFR-amplified HNSCC PDX models in combination with fractionated irradiation [65]. Our preliminary data in HNSCC models spurred interest in a possible role of wild-type HRAS in innate resistance to standard-of-care drugs such as cisplatin and cetuximab as well as targeted agents in clinical development in HNSCC, including CDK4/6 inhibitors and PI3K pathway drugs. As shown in Figure 3, tipifarnib co-treatment sensitized the HRAS-overexpressing HN2594 PDX model to all four classes of drugs, inducing consistent regressions in all combination regimens, despite only the CDK4/ 6 inhibitor palbociclib being significantly active as a single agent in this experiment. In expanded tests, tipifarnib enhanced cisplatin activity in 3/12 HRAS wild-type models examined, all of which overexpressed the HRAS gene, as described previously [66]. Tipifarnib also increased tumor growth inhibition with palbociclib in the majority of HRAS high models tested, but cetuximab was highly active in all four PDX studied, precluding assessment of this combination in these models; previous work suggests that HRAS signaling is a key driver of cetuximab resistance in experimental models and in the clinic [61]. In a third study focused on PI3K pathway combinations, synergy was noted with both the mTOR kinase inhibitor TAK-228 (sapanisertib) and the PI3Ka inhibitor BYL-719 (alpelisib), including in HRAS or PIK3CA mutant (20\% of HNSCC) [67], PIK3CA-amplified (15\%) [68] or HRAS-overexpressing (30\%) (Figure 3) models, and this combination has previously been shown to be synergistic in CDX systems [69], suggesting that simultaneous blockade of these two prominent oncogenic pathways could offer potential benefit in a broad population of HNSCC patients.

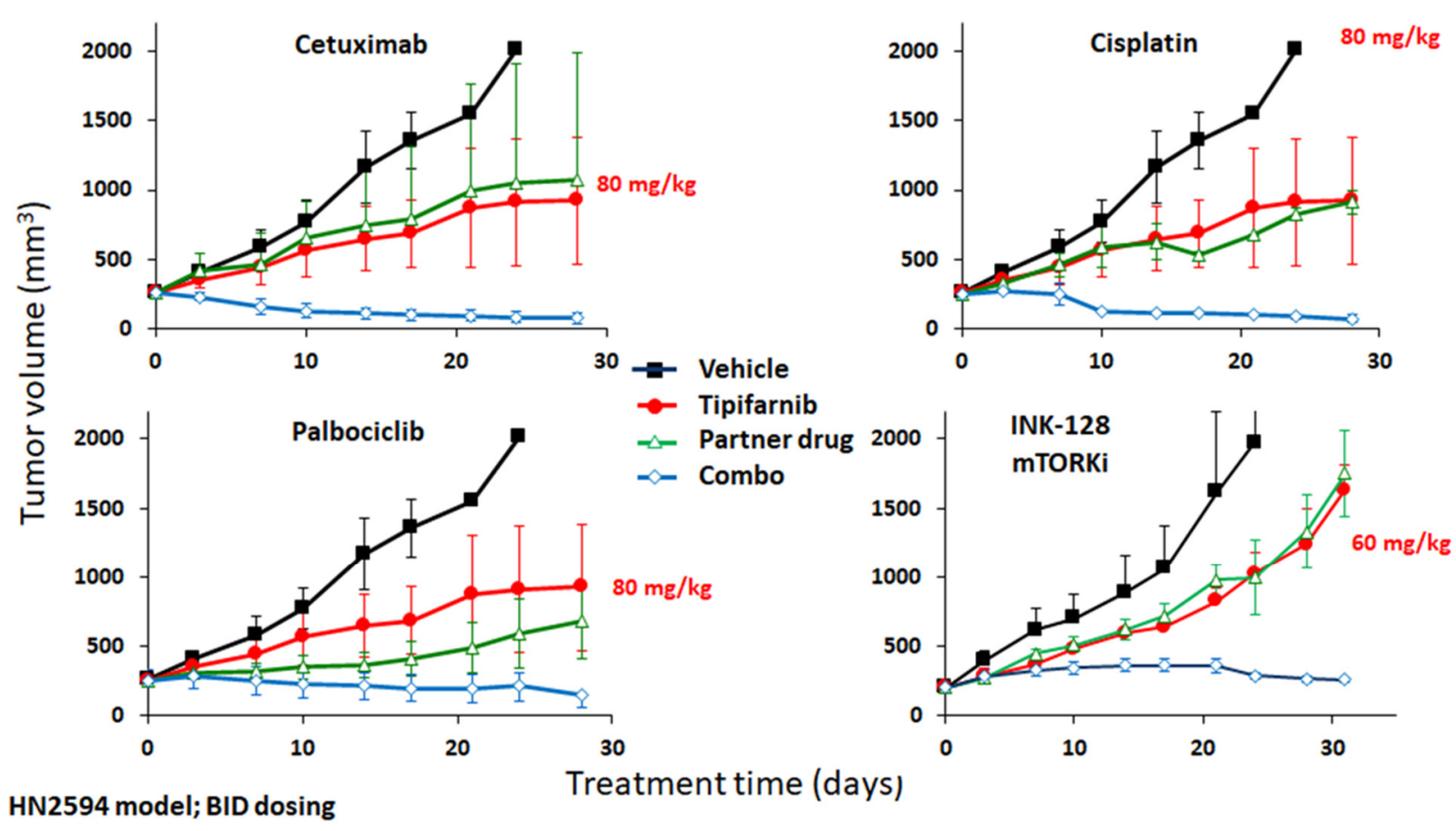

Figure 3. Tipifarnib displays additive or synergistic anti-tumor activity with a variety of partner drugs in HRASoverexpressing patient-derived xenograft (PDX) models. BALB/c nu/nu or SCID mice were inoculated subcutaneously with 2-3 mm tumor fragments, the PDX were allowed to establish to $250-350 \mathrm{~mm}^{3}$ and the animals were randomized into groups of three before being dosed with vehicle or tipifarnib (60-80 mg/ $\mathrm{kg}$ BID as labeled above) alone or in combination with cetuximab (1 mg/mouse IP QW), cisplatin (5 mg/kg Q3D PO), palbociclib (40 mg/kg QD PO), or INK-128 (2 mg/ kg QD PO). 
In summary, extensive studies in panels of PDX models indicate that both mutant and overexpressed HRAS contribute significantly to the proliferation, survival, and innate drug resistance of HNSCC cells in vivo. HRAS is the predominant RAS isoform in squamous epithelial cells and the SCCs derived from them [55] and so may play a wider role. Although HRAS activity has previously been reported to contribute to most hallmarks of cancer [40] and to drive clinical resistance to cetuximab [42,43], it is also likely that HRAS-independent mechanisms contribute, at least in part, to the antitumor activity of tipifarnib in HNSCC models. Dozens of proteins are dependent upon farnesylation for membrane insertion and function [70]. In the next section, we explore the potential of farnesyltransferase inhibition to anchor combination regimens through mechanisms independent of HRAS.

\section{Combination Approaches with FTIs in SCCs and Other Solid Tumors}

Although RAS is known to play a key role in innate resistance to a variety of therapeutics used in SCCs, including platinum-based chemotherapy and anti-EGFR antibodies $[43,66]$, and HRAS inactivation sensitizes HNSCC PDX tumors to a range of drugs in mice (Figure 3), it has been established that much of the documented antineoplastic activity of FTIs is mediated by effects on proteins other than RAS [71,72]. For example, several lines of evidence suggest that RHOB farnesylation may have contextual roles in tumor progression and survival. RHOB expression in Rat1 cells induces proliferation, which can be inhibited by FTIs [73]. RHOB has also been shown to be a direct regulator of phosphatase 2A (PP2A) activity via recruitment of the B55 subunit [74]. During lung cancer progression, downregulation of RHOB may inhibit PP2A activity, leading to activation of the Akt1-Trio-Rac1 axis, triggering cell migration and invasion. Furthermore, an AKT-dependent mechanism has been suggested to underlie RHOB-driven resistance to EGFR inhibitors in EGFR-mutant NSCLC models [75]. Another potential target of FTIs is RHEB (RAS homolog enriched in brain), a GTPase with two isoforms (RHEB1 and RHEB2) that are commonly upregulated in transformed cells and human cancer cell lines. RHEB binds and activates the mechanistic target of rapamycin (mTOR), a regulator of tumor cell growth, survival, and metabolism [76,77]. It is thought that mTOR is activated via farnesylation-dependent transient interactions of RHEB with the mTORC1 complex in lysosomal membranes [78]. Human RHEB1 and RHEB2 have been shown in vitro to be substrates for FTase, and treatment of cells with FTIs inhibits RHEB prenylation. Basso et al. demonstrated that treatment of MCF-7 cells with lonafarnib inhibited RHEB farnesylation, resulting in inhibition of DNA synthesis and S6 kinase activation. Furthermore, it was found that lonafarnib enhanced tamoxifen- and taxane-driven apoptosis, supporting the combination of FTIs with standard-of-care agents. RHEB-mTOR signaling has also been implicated in resistance to antineoplastic therapies [79]; thus, combination approaches may bypass these resistance mechanisms [80]. Recent findings by Mahkov et al. demonstrated that 786-O renal carcinoma cells expressing prenylation-incompetent RHEB display robust apoptosis in response to sunitinib treatment [81]. Moreover, the investigators examined the anti-tumor effect of sunitinib in combination with lonafarnib using mice bearing clear cell renal cell carcinoma (ccRCC) xenograft tumors. Monotherapy with either sunitinib or lonafarnib showed a moderate decrease in tumor growth; however, co-administration resulted in impressive reductions in tumor volume. Thus, FTIs may offer a means to circumvent sunitinib resistance, perhaps through prevention of RHEB localization to lysosomal membranes and subsequent downstream activation of mTOR signaling.

Several additional families of proteins with functional roles in proliferation, invasion and other hallmarks of cancer are dependent upon farnesylation for appropriate intracellular localization and activity. Centromere protein-E (CENP-)E and CENP-F have also been shown to be FTI targets. CENP-E is a centromere-associated kinesin motor protein that functions in microtubule attachment to kinetochores, which is required for the separation of sister chromatids during mitosis $[82,83]$. CENP-F is a cell cycle-regulated passenger protein which also has mitotic function [84]. Both CENP-E and CENP-F are farnesylated proteins whose prenylation is inhibited by FTI treatment [85], subsequently preventing CENP-E 
association with microtubules and reducing levels of CENP-F at the kinetochores [85,86]. Similarly, the PRL family of protein tyrosine phosphatases (PTPS), also known as PTPCAAX proteins, are a unique subfamily of PTPs that regulate cell growth and mitosis and have been shown to be upregulated in numerous human tumor cell lines and implicated in progression of several tumor types [87-89]. The PRL family includes three members, all of which are farnesylated. Al three forms traffic to the plasma membrane in transfected $\mathrm{CHO}$ cells, localization of which is inhibited by FTIs [90].

Some farnesylated substrates carry unknown significance for cancer but may still provide clinical utility, such as the DnaJ homologs which serve as co-chaperones and stimulate the ATPase activity of Hsp70, a cancer-associated protein [91]. One homolog, HDJ2, is a farnesylated protein whose prenylation status is used as a pharmacodynamic (PD) biomarker for FTase inhibition in clinical trials [92]. The functional significance of HDJ2 farnesylation remains unclear. Nuclear lamins (e.g., lamin A, lamin B), proteins that are required for nuclear envelope assembly, were some of the first proteins shown to be prenylated [93]. Similar to HDJ2, the functional consequence of lamin prenylation is unknown but may assist in the targeting of prelamins to the nuclear membrane. A mutation in prelamin $A$ occurs in children with Hutchinson-Gilford progeria syndrome (HGPS), a debilitating and fatal disease characterized by premature aging. FTIs have been shown to reverse the abnormal nuclear phenotype in cells derived from HGPS patients [94], and the FTI lonafarnib was recently approved for therapy of this devastating rare disease [95].

In some instances, farnesyltransferase inhibition has been found to mediate antitumor activity, but the farnesylated substrate underlying the effect remains to be confirmed. For instance, tipifarnib and other FTIs have been suggested to act as antiangiogenic agents in several tumor types including HNSCC $[40,46]$, but the mechanisms are yet to be elucidated [44] and may be hard to delineate from indirect downstream consequences of inhibiting another target, such as HRAS [40]. Similarly, FTIs have been shown to rapidly trigger the production of reactive oxygen species (ROS) [96]. Though the mechanism of ROS generation remains unclear, the consequences include DNA damage responses, such as activation of DNA repair proteins and induction of RHOB [96]. In turn, RHOB may sensitize cancer cells to DNA damage-induced apoptosis following genotoxic stress [97]. FTIs may also offer the potential to modulate antitumor immunity. RAS-MAPK signaling drives expression of the CD274 gene leading to PDL-1 overexpression [98] but also downregulates MHC Class I expression, reducing immunogenicity and undermining the effectiveness of immune checkpoint inhibitors [99]. Therefore, FTI treatment might enhance responsiveness of HRAS-dependent SCCs to immunotherapy.

CXCL12 (or SDF1) is a potent immunoregulatory chemokine and CXCL12-CXCR4 signaling is associated with resistance to immunotherapy in HNSCC [100]. Intriguingly, we have recently reported that CXCL12 production by stromal fibroblasts, the predominant CXCL12-producing cell in solid tumors, can be inhibited by tipifarnib in vitro [101]. Further studies are ongoing in our laboratory to characterize this novel FTI activity and the potential of FTIs to enhance immunotherapy in SCC models. CXCL12 also shows promise as a biomarker guiding FTI therapy in T-cell lymphoma patients. Recently, the effect of tipifarnib on the CXCL12 axis was investigated in an open-label, Phase 2 study in relapsed or refractory peripheral T-cell lymphoma [102]. Tumor gene expression data were available for 12 of the 18 evaluable patients. Five of those patients had elevated CXCL12 expression and experienced tumor size reductions and $>6$-month median time to progress following tipifarnib treatment. Thus, tipifarnib may be a promising therapeutic approach in this patient population.

It is likely that protein farnesylation plays an actionable role in many oncogenic signaling pathways. Indeed, there are hundreds of proteins with CAAX motifs that are potentially farnesylated [72], although the true number of farnesylation-dependent proteins is probably several dozen in most cell types [70]. Given this pleiotropy, it is perhaps counterintuitive that tipifarnib has been evaluated in more than 5000 patients and has been generally well-tolerated with a clearly delineated toxicity profile when used 
at doses that sharply reduce farnesylation of several PD biomarkers in vivo [92]. Several mitigating factors, including redundancy with farnesylation-independent orthologs or collateral signaling pathways, varying sensitivity to FTase activity between substrates [70], and pharmacokinetic compartmentalization, may render FTIs more selective in vivo, but mounting evidence supports the notion that farnesylated target oncoproteins including HRAS, RHEB, and RHOB could be exploited as part of FTI-anchored combination regimens in SCCs and a range of other tumor types.

\section{Conclusions}

In summary, preclinical murine studies, in-depth oncogenic analyses, and ongoing clinical investigation in patients with mutant HRAS tumors may support tipifarnib as a novel precision therapeutic approach for HNSCC and other cancers. Recent advances in genomic and cellular studies have led to the identification of HRAS mutations as drivers of tumor growth in a subset of HNSCC. These mutations in an oncogene that is uniquely sensitive to inhibition of farnesylation appear to sensitize the tumors to farnesyl transferase inhibitors such as tipifarnib, as supported by animal models and ongoing clinical trials. In addition, preclinical studies in PDX models overexpressing HRAS have demonstrated that tipifarnib sensitizes these tumors to several drugs in clinical use in SCCs, suggesting that the benefit of tipifarnib may be extended to include those patients with HRAS overexpressing tumors when used in combination with drugs such as cetuximab, alpelisib, and cisplatin. Furthermore, inhibition of other farnesylated proteins, such as RHEB and RHOB, may help overcome resistance to standard therapies in SCCs and additional tumor types.

Author Contributions: M.L. provided clinical data content and overview of tipifarnib as in Section 1; F.B. provided content and overview of Section 2; S.M. and L.K. provided content and overview of Section 3 and the conclusions, as well as final editing. All authors have read and agreed to the published version of the manuscript.

Funding: This was supported by research funding from Kura Oncology.

Acknowledgments: JetPub Scientific Communications LLC, supported by Kura Oncology, Inc., assisted in the preparation of this manuscript, in accordance with Good Publication Practice (GPP3) guidelines.

Conflicts of Interest: All authors are full-time employees of Kura Oncology.

\section{References}

1. Stokoe, D.; Macdonald, S.G.; Cadwallader, K.; Symons, M.; Hancock, J.F. Activation of Raf as a result of recruitment to the plasma membrane. Science 1994, 264, 1463-1467. [CrossRef] [PubMed]

2. Keely, P.J.; Westwick, J.K.; Whitehead, I.P.; Der, C.J.; Parise, L.V. Cdc42 and Rac1 induce integrin-mediated cell motility and invasiveness through PI(3)K. Nature 1997, 390, 632-636. [CrossRef] [PubMed]

3. Kennedy, S.G.; Wagner, A.J.; Conzen, S.D.; Jordán, J.; Bellacosa, A.; Tsichlis, P.N.; Hay, N. The PI 3-kinase/Akt signaling pathway delivers an anti-apoptotic signal. Genes Dev. 1997, 11, 701-713. [CrossRef] [PubMed]

4. Gille, H.; Downward, J. Multiple Ras effector pathways contribute to G1 cell cycle progression. J. Biol. Chem. 1999, 274, 22033-22040. [CrossRef]

5. Keely, P.J.; Rusyn, E.V.; Cox, A.D.; Parise, L.V. R-Ras signals through specific integrin $\alpha$ cytoplasmic domains to promote migration and invasion of breast epithelial cells. J. Cell Biol. 1999, 145, 1077-1088. [CrossRef]

6. Rowinsky, E.K.; Windle, J.J.; Von Hoff, D.D. Ras protein farnesyltransferase: A strategic target for anticancer therapeutic development. J. Clin. Oncol. 1999, 17, 3631-3652. [CrossRef]

7. Adjei, A.A. Blocking oncogenic ras signaling in cancer. Rev. J. Natl. Cancer Inst. 2001, 93, 1062-1074. [CrossRef]

8. Bos, J.L. Ras oncogenes in human cancer: A review. Cancer Res. 1989, 49, 4682-4689.

9. Moore, A.R.; Rosenberg, S.C.; McCormick, F.; Malek, S. RAS-targeted therapies: Is the undruggable drugged? Nat. Rev. Drug Discov. 2020, 19, 533-552. [CrossRef]

10. Mulcahy, L.S.; Smith, M.R.; Stacey, D.W. Requirement for ras proto-oncogene function during serum-stimulated growth of NIH 3T3 cells. Nature 1985, 313, 241-243. [CrossRef]

11. Shirasawa, S.; Furuse, M.; Yokoyama, N.; Sasazuki, T. Altered growth of human colon cancer cell lines disrupted at activated Ki-ras. Science 1993, 260, 85-88. [CrossRef]

12. Prior, I.A.; Hancock, J.F. Compartmentalization of Ras proteins. J. Cell Sci. 2001, 114, 1603-1608. [CrossRef] 
13. Hancock, J.F.; Paterson, H.; Marshall, C.J. A polybasic domain or palmitoylation is required in addition to the CAAX motif to localize p21ras to the plasma membrane. Cell 1990, 63, 133-139. [CrossRef]

14. Reiss, Y.; Goldstein, J.L.; Seabra, M.C.; Casey, P.J.; Brown, M.S. Inhibition of purified p21ras farnesyl:protein transferase by Cys-AAX tetrapeptides. Cell 1990, 62, 81-88. [CrossRef]

15. James, G.L.; Goldstein, J.L.; Brown, M.S.; Rawson, T.E.; Somers, T.C.; McDowell, R.S.; Crowley, C.W.; Lucas, B.K.; Levinson, A.D.; Marsters, J.C. Benzodiazepine peptidomimetics: Potent inhibitors of Ras farnesylation in animal cells. Science 1993, 260, 1937-1942. [CrossRef] [PubMed]

16. Qian, Y.; Blaskovich, M.A.; Saleem, M.; Seong, C.M.; Wathen, S.P.; Hamilton, A.D.; Sebti, S.M. Design and structural requirements of potent peptidomimetic inhibitors of p21(ras) farnesyltransferase. J. Biol. Chem. 1994, 269, 12410-12413. [CrossRef]

17. Vogt, A.; Qian, Y.; Blaskovich, M.A.; Fossum, R.D.; Hamilton, A.D.; Sebti, S.M. A non-peptide mimetic of Ras-CAAX: Selective inhibition of farnesyltransferase and Ras processing. J. Biol. Chem. 1995, 270, 660-664. [CrossRef]

18. Nigam, M.; Seong, C.M.; Qian, Y.; Hamilton, A.D.; Sebti, S.M. Potent inhibition of human tumor p21(ras) farnesyltransferase by A1A2- lacking p21(ras) CA1A2X peptidomimetics. J. Biol. Chem. 1993, 268, 20695-20698. [CrossRef]

19. Long, S.B.; Hancock, P.J.; Kral, A.M.; Hellinga, H.W.; Beese, L.S. The crystal structure of human protein farnesyltransferase reveals the basis for inhibition by CaaX tetrapeptides and their mimetics. Proc. Natl. Acad. Sci. USA 2001, 98, 12948-12953. [CrossRef]

20. End, D.W.; Smets, G.; Todd, A.V.; Applegate, T.L.; Fuery, C.J.; Angibaud, P.; Venet, M.; Sanz, G.; Poignet, H.; Skrzat, S.; et al. Characterization of the antitumor effects of the selective farnesyl protein transferase inhibitor R115777 in vivo and in vitro. Cancer Res. 2001, 61, 131-137.

21. Crul, M.; de Klerk, G.J.; Swart, M.; van't Veer, L.J.; de Jong, D.; Boerrigter, L.; Palmer, P.A.; Bol, C.J.; Tan, H.; de Gast, G.C.; et al. Phase I clinical and pharmacologic study of chronic oral administration of the farnesyl protein transferase inhibitor R115777 in advanced cancer. J. Clin. Oncol. 2002, 20, 2726-2735. [CrossRef]

22. Zujewski, J.; Horak, I.D.; Bol, C.J.; Woestenborghs, R.; Bowden, C.; End, D.W.; Piotrovsky, V.K.; Chiao, J.; Belly, R.T.; Todd, A.; et al. Phase I and pharmacokinetic study of farnesyl protein transferase inhibitor R115777 in advanced cancer. J. Clin. Oncol. 2000, 18, 927-941. [CrossRef]

23. Cohen, S.J.; Ho, L.; Ranganathan, S.; Abbruzzese, J.L.; Alpaugh, R.K.; Beard, M.; Lewis, N.L.; McLaughlin, S.; Rogatko, A.; Perez-Ruixo, J.J.; et al. Phase II and pharmacodynamic study of the farnesyltransferase inhibitor R115777 as initial therapy in patients with metastatic pancreatic adenocarcinoma. J. Clin. Oncol. 2003, 21, 1301-1306. [CrossRef]

24. Alsina, M.; Fonseca, R.; Wilson, E.F.; Belle, A.N.; Gerbino, E.; Price-Troska, T.; Overton, R.M.; Ahmann, G.; Bruzek, L.M.; Adjei, A.A.; et al. Farnesyltransferase inhibitor tipifarnib is well tolerated, induces stabilization of disease, and inhibits farnesylation and oncogenic/tumor survival pathways in patients with advanced multiple myeloma. Blood 2004, 103, 3271-3277. [CrossRef]

25. Adjei, A.A.; Mauer, A.; Bruzek, L.; Marks, R.S.; Hillman, S.; Geyer, S.; Hanson, L.J.; Wright, J.J.; Erlichman, C.; Kaufmann, S.H.; et al. Phase II study of the farnesyl transferase inhibitor R115777 in patients with advanced non-small-cell lung cancer. J. Clin. Oncol. 2003, 21, 1760-1766. [CrossRef]

26. Rao, S.; Cunningham, D.; de Gramont, A.; Scheithauer, W.; Smakal, M.; Humblet, Y.; Kourteva, G.; Iveson, T.; Andre, T.; Dostalova, J.; et al. Phase III double-blind placebo-controlled study of farnesyl transferase inhibitor R115777 in patients with refractory advanced colorectal cancer. J. Clin. Oncol. 2004, 22, 3950-3957. [CrossRef]

27. Van Cutsem, E.; van de Velde, H.; Karasek, P.; Oettle, H.; Vervenne, W.L.; Szawlowski, A.; Schoffski, P.; Post, S.; Verslype, C.; Neumann, H.; et al. Phase III trial of gemcitabine plus tipifarnib compared with gemcitabine plus placebo in advanced pancreatic cancer. J. Clin. Oncol. 2004, 22, 1430-1438. [CrossRef] [PubMed]

28. Zhang, F.L.; Kirschmeier, P.; Carr, D.; James, L.; Bond, R.W.; Wang, L.; Patton, R.; Windsor, W.T.; Syto, R.; Zhang, R.; et al. Characterization of Ha-Ras, N-Ras, Ki-Ras4A, and Ki-Ras4B as in vitro substrates for farnesyl protein transferase and geranylgeranyl protein transferase type I. J. Biol. Chem. 1997, 272, 10232-10239. [CrossRef] [PubMed]

29. Whyte, D.B.; Kirschmeier, P.; Hockenberry, T.N.; Nunez-Oliva, I.; James, L.; Catino, J.J.; Bishop, W.R.; Pai, J.K. K- and N-Ras are geranylgeranylated in cells treated with farnesyl protein transferase inhibitors. J. Biol. Chem. 1997, 272, 14459-14464. [CrossRef] [PubMed]

30. Fukahori, M.; Yoshida, A.; Hayashi, H.; Yoshihara, M.; Matsukuma, S.; Sakuma, Y.; Koizume, S.; Okamoto, N.; Kondo, T.; Masuda, M.; et al. The associations between ras mutations and clinical characteristics in follicular thyroid tumors: New insights from a single center and a large patient cohort. Thyroid 2012, 22, 683-689. [CrossRef]

31. Volante, M.; Rapa, I.; Gandhi, M.; Bussolati, G.; Giachino, D.; Papotti, M.; Nikiforov, Y.E. RAS mutations are the predominant molecular alteration in poorly differentiated thyroid carcinomas and bear prognostic impact. J. Clin. Endocrinol. Metab. 2009, 94, 4735-4741. [CrossRef]

32. Ricarte-Filho, J.C.; Ryder, M.; Chitale, D.A.; Rivera, M.; Heguy, A.; Ladanyi, M.; Janakiraman, M.; Solit, D.; Knauf, J.A.; Tuttle, R.M.; et al. Mutational profile of advanced primary and metastatic radioactive iodine-refractory thyroid cancers reveals distinct pathogenetic roles for BRAF, PIK3CA, and AKT1. Cancer Res. 2009, 69, 4885-4893. [CrossRef]

33. Moura, M.M.; Cavaco, B.M.; Pinto, A.E.; Leite, V. High prevalence of RAS mutations in RET-negative sporadic medullary thyroid carcinomas. J. Clin. Endocrinol. Metab. 2011, 96, 863-868. [CrossRef]

34. Agrawal, N.; Frederick, M.J.; Pickering, C.R.; Bettegowda, C.; Chang, K.; Li, R.J.; Fakhry, C.; Xie, T.X.; Zhang, J.; Wang, J.; et al. Exome sequencing of head and neck squamous cell carcinoma reveals inactivating mutations in NOTCH1. Science 2011, 333, 1154-1157. [CrossRef] [PubMed] 
35. Untch, B.R.; Dos Anjos, V.; Garcia-Rendueles, M.E.R.; Knauf, J.A.; Krishnamoorthy, G.P.; Saqcena, M.; Bhanot, U.K.; Socci, N.D.; Ho, A.L.; Ghossein, R.; et al. Tipifarnib inhibits HRAS-driven dedifferentiated thyroid cancers. Cancer Res. 2018, 78, $4642-4657$. [CrossRef]

36. de Bruin, E.C.; Cowell, C.; Warne, P.H.; Jiang, M.; Saunders, R.E.; Melnick, M.A.; Gettinger, S.; Walther, Z.; Wurtz, A.; Heynen, G.J.; et al. Reduced NF1 expression confers resistance to EGFR inhibition in lung cancer. Cancer Discov. 2014, 4, 606-619. [CrossRef] [PubMed]

37. Whittaker, S.R.; Theurillat, J.P.; Van Allen, E.; Wagle, N.; Hsiao, J.; Cowley, G.S.; Schadendorf, D.; Root, D.E.; Garraway, L.A. A genome-Scale RNA interference screen implicates NF1 loss in resistance to RAF inhibition. Cancer Discov. 2013, 3, 351-362. [CrossRef]

38. Beauchamp, E.M.; Woods, B.A.; Dulak, A.M.; Tan, L.; Xu, C.; Gray, N.S.; Bass, A.J.; Wong, K.K.; Meyerson, M.; Hammerman, P.S. Acquired resistance to dasatinib in lung cancer cell lines conferred by DDR2 gatekeeper mutation and NF1 loss. Mol. Cancer Ther. 2014, 13, 475-482. [CrossRef] [PubMed]

39. Johannessen, C.M.; Johnson, L.A.; Piccioni, F.; Townes, A.; Frederick, D.T.; Donahue, M.K.; Narayan, R.; Flaherty, K.T.; Wargo, J.A.; Root, D.E.; et al. A melanocyte lineage program confers resistance to MAP kinase pathway inhibition. Nature 2013, 504, 138-142. [CrossRef]

40. Gilardi, M.; Wang, Z.; Proietto, M.; Chilla, A.; Calleja-Valera, J.L.; Goto, Y.; Vanoni, M.; Janes, M.R.; Mikulski, Z.; Gualberto, A.; et al. Tipifarnib as a precision therapy for HRAS-mutant head and neck squamous cell carcinomas. Mol. Cancer Ther. 2020, 19, 1784-1796. [CrossRef]

41. Hoadley, K.A.; Yau, C.; Hinoue, T.; Wolf, D.M.; Lazar, A.J.; Drill, E.; Shen, R.; Taylor, A.M.; Cherniack, A.D.; Thorsson, V.; et al. Cell-of-origin patterns dominate the molecular classification of 10,000 tumors from 33 types of cancer. Cell 2018, 173, 291-304.e6. [CrossRef]

42. Braig, F.; Voigtlaender, M.; Schieferdecker, A.; Busch, C.J.; Laban, S.; Grob, T.; Kriegs, M.; Knecht, R.; Bokemeyer, C.; Binder, M. Liquid biopsy monitoring uncovers acquired RAS-mediated resistance to cetuximab in a substantial proportion of patients with head and neck squamous cell carcinoma. Oncotarget 2016, 7, 42988-42995. [CrossRef] [PubMed]

43. Rampias, T.; Giagini, A.; Siolos, S.; Matsuzaki, H.; Sasaki, C.; Scorilas, A.; Psyrri, A. RAS/PI3K crosstalk and cetuximab resistance in head and neck squamous cell carcinoma. Clin. Cancer Res. 2014, 20, 2933-2946. [CrossRef] [PubMed]

44. Scott, A.N.; Hetheridge, C.; Reynolds, A.R.; Nayak, V.; Hodivala-Dilke, K.; Mellor, H. Farnesyltransferase inhibitors target multiple endothelial cell functions in angiogenesis. Angiogenesis 2008, 11, 337-346. [CrossRef]

45. Han, J.Y.; Oh, S.H.; Morgillo, F.; Myers, J.N.; Kim, E.; Hong, W.K.; Lee, H.Y. Hypoxia-inducible factor $1 \alpha$ and antiangiogenic activity of farnesyltransferase inhibitor SCH66336 in human aerodigestive tract cancer. J. Natl. Cancer Inst. 2005, 97, 1272-1286. [CrossRef]

46. Oh, S.H.; Kim, W.Y.; Kim, J.H.; Younes, M.N.; El-Naggar, A.K.; Myers, J.N.; Kies, M.; Cohen, P.; Khuri, F.; Hong, W.K.; et al. Identification of insulin-like growth factor binding protein-3 as a farnesyl transferase inhibitor SCH66336-induced negative regulator of angiogenesis in head and neck squamous cell carcinoma. Clin. Cancer Res. 2006, 12, 653-661. [CrossRef]

47. Kiessling, M.; Curioni Fontecedro, A.; Samaras, P.; Scharl, M.; Rogler, G. Mutant HRAS as novel target for MEK and mTOR inhibitors. J. Clin. Oncol. 2015, 33, 11082. [CrossRef]

48. Ho, A.L.; Hanna, G.J.; Scholz, C.R.; Gualberto, A.; Park, S.H. Preliminary activity of tipifarnib in tumors of the head and neck, salivary gland and urothelial tract with HRAS mutations. J. Clin. Oncol. 2020, 38, 6504. [CrossRef]

49. Takano, T.; Ohe, Y.; Sakamoto, H.; Tsuta, K.; Matsuno, Y.; Tateishi, U.; Yamamoto, S.; Nokihara, H.; Yamamoto, N.; Sekine, I.; et al. Epidermal growth factor receptor gene mutations and increased copy numbers predict gefitinib sensitivity in patients with recurrent non-small-cell lung cancer. J. Clin. Oncol. 2005, 23, 6829-6837. [CrossRef] [PubMed]

50. Smrdel, U.; Kovač, V. Erlotinib in previously treated non-small-cell lung cancer. Radiol. Oncol. 2006, 40. [CrossRef]

51. Temam, S.; Kawaguchi, H.; El-Naggar, A.K.; Jelinek, J.; Tang, H.; Liu, D.D.; Lang, W.; Issa, J.P.; Lee, J.J.; Mao, L. Epidermal growth factor receptor copy number alterations correlate with poor clinical outcome in patients with head and neck squamous cancer. $J$. Clin. Oncol. 2007, 25, 2164-2170. [CrossRef] [PubMed]

52. Hansen, A.R.; Siu, L.L. Epidermal growth factor receptor targeting in head and neck cancer: Have we been just skimming the surface? J. Clin. Oncol. 2013, 31, 1381-1383. [CrossRef] [PubMed]

53. Byeon, H.K.; Ku, M.; Yang, J. Beyond EGFR inhibition: Multilateral combat strategies to stop the progression of head and neck cancer. Exp. Mol. Med. 2019, 51, 1-14. [CrossRef] [PubMed]

54. Juergens, R.A.; Bratman, S.V.; Tsao, M.S.; Laurie, S.A.; Sara Kuruvilla, M.; Razak, A.R.A.; Hansen, A.R. Biology and patterns of response to EGFR-inhibition in squamous cell cancers of the lung and head \& neck. Cancer Treat. Rev. 2017, 54, 43-57. [PubMed]

55. Cancer genome atlas network comprehensive genomic characterization of head and neck squamous cell carcinomas. Nature 2015, 517, 576-582. [CrossRef] [PubMed]

56. Kulkarni, S.; Bill, A.; Godse, N.R.; Khan, N.I.; Kass, J.I.; Kemp, C.; Davis, K.; Bertrand, C.A.; Vyas, A.R.; Douglas, E.; et al. TMEM16A/ANO1 suppression improves response to antibody-mediated targeted therapy of EGFR and HER2/ERBB2. Genes Chromosomes Cancer 2017, 56, 460-471. [CrossRef]

57. Hermida-Prado, F.; Menéndez, S.; Albornoz-Afanasiev, P.; Granda-Diaz, R.; Álvarez-Teijeiro, S.; Villaronga, M.; Allonca, E.; Alonso-Durán, L.; León, X.; Alemany, L.; et al. Distinctive expression and amplification of genes at 11q13 in relation to HPV status with impact on survival in head and neck cancer patients. J. Clin. Med. 2018, 7, 501. [CrossRef] 
58. Rabinowits, G.; Haddad, R.I. Overcoming resistance to EGFR inhibitor in head and neck cancer: A review of the literature. Oral Oncol. 2012, 48, 1085-1089. [CrossRef]

59. Zhu, H.; Wang, C.; Wang, J.; Chen, D.; Deng, J.; Deng, J.; Fan, J.; Badakhshi, H.; Huang, X.; Zhang, L.; et al. A subset of esophageal squamous cell carcinoma patient-derived xenografts respond to cetuximab, which is predicted by high EGFR expression and amplification. J. Thorac. Dis. 2018, 10, 5328-5338. [CrossRef]

60. Bonomi, P.D.; Gandara, D.; Hirsch, F.R.; Kerr, K.M.; Obasaju, C.; Paz-Ares, L.; Bellomo, C.; Bradley, J.D.; Bunn, P.A.; Culligan, M.; et al. Predictive biomarkers for response to EGFR-directed monoclonal antibodies for advanced squamous cell lung cancer. Ann. Oncol. 2018, 29, 1701-1709. [CrossRef]

61. Pirker, R.; Pereira, J.R.; Von Pawel, J.; Krzakowski, M.; Ramlau, R.; Park, K.; De Marinis, F.; Eberhardt, W.E.E.; Paz-Ares, L.; Störkel, S.; et al. EGFR expression as a predictor of survival for first-line chemotherapy plus cetuximab in patients with advanced non-small-cell lung cancer: Analysis of data from the phase 3 FLEX study. Lancet Oncol. 2012, 13, 33-42. [CrossRef]

62. Khambata-Ford, S.; Harbison, C.T.; Hart, L.L.; Awad, M.; Xu, L.A.; Horak, C.E.; Dakhil, S.; Hermann, R.C.; Lynch, T.J.; Weber, M.R. Analysis of potential predictive markers of cetuximab benefit in BMS099, a phase III study of cetuximab and first-line taxane/carboplatin in advanced non-small-cell lung cancer. J. Clin. Oncol. 2010, 28, 918-927. [CrossRef]

63. Su, S.C.; Lin, C.W.; Liu, Y.F.; Fan, W.L.; Chen, M.K.; Yu, C.P.; Yang, W.E.; Su, C.W.; Chuang, C.Y.; Li, W.H.; et al. Exome sequencing of oral squamous cell carcinoma reveals molecular subgroups and novel therapeutic opportunities. Theranostics 2017, 7, 1088-1099. [CrossRef]

64. Campbell, J.D.; Yau, C.; Bowlby, R.; Liu, Y.; Brennan, K.; Fan, H.; Taylor, A.M.; Wang, C.; Walter, V.; Akbani, R.; et al. Genomic, Pathway Network, and Immunologic Features Distinguishing Squamous Carcinomas. Cell Rep. 2018, 23, 194-212.e6. [CrossRef]

65. Koi, L.; Löck, S.; Linge, A.; Thurow, C.; Hering, S.; Baumann, M.; Krause, M.; Gurtner, K. EGFR-amplification plus gene expression profiling predicts response to combined radiotherapy with EGFR-inhibition: A preclinical trial in 10 HNSCC-tumour-xenograft models. Radiother. Oncol. 2017, 124, 496-503. [CrossRef] [PubMed]

66. Rampias, T.; Hoxhallari, L.; Avgeris, M.; Kanaki, Z.; Telios, D.; Giotakis, E.; Giotakis, I.; Scorilas, A.; Psyrri, A.; Klinakis, A. Sensitizing HRAS overexpressing head and neck squamous cell carcinoma (HNSCC) to chemotherapy. Ann. Oncol. 2019, 30, v462-v463. [CrossRef]

67. Mountzios, G.; Rampias, T.; Psyrri, A. The mutational spectrum of squamous-cell carcinoma of the head and neck: Targetable genetic events and clinical impact. Ann. Oncol. Off. J. Eur. Soc. Med. Oncol. 2014, 25, 1889-1900. [CrossRef] [PubMed]

68. Lui, V.W.Y.; Hedberg, M.L.; Li, H.; Vangara, B.S.; Pendleton, K.; Zeng, Y.; Lu, Y.; Zhang, Q.; Du, Y.; Gilbert, B.R.; et al. Frequent mutation of the PI3K pathway in head and neck cancer defines predictive biomarkers. Cancer Discov. 2013, 3, 761-769. [CrossRef]

69. Ruicci, K.M.; Pinto, N.; Khan, M.I.; Yoo, J.; Fung, K.; MacNeil, D.; Mymryk, J.S.; Barrett, J.W.; Nichols, A.C. ERK-TSC2 signalling in constitutively-active HRAS mutant HNSCC cells promotes resistance to PI3K inhibition. Oral Oncol. 2018, 84, 95-103. [CrossRef] [PubMed]

70. Storck, E.M.; Morales-Sanfrutos, J.; Serwa, R.A.; Panyain, N.; Lanyon-Hogg, T.; Tolmachova, T.; Ventimiglia, L.N.; Martin-Serrano, J.; Seabra, M.C.; Wojciak-Stothard, B.; et al. Dual chemical probes enable quantitative system-wide analysis of protein prenylation and prenylation dynamics. Nat. Chem. 2019, 11, 552-561. [CrossRef]

71. Basso, A.D.; Kirschmeier, P.; Bishop, W.R. Farnesyl transferase inhibitors. J. Lipid Res. 2006, 47, 15-31. [CrossRef] [PubMed]

72. Pan, J.; Yeung, S.J. Recent advances in understanding the antineoplastic mechanisms of farnesyltransferase inhibitors. Cancer Res. 2005, 9109-9113. [CrossRef] [PubMed]

73. Lebowitz, P.F.; Davide, J.P.; Prendergast, G.C. Evidence that farnesyltransferase inhibitors suppress Ras transformation by interfering with Rho activity. Mol. Cell. Biol. 1995, 15, 6613-6622. [CrossRef] [PubMed]

74. Bousquet, E.; Calvayrac, O.; Mazières, J.; Lajoie-Mazenc, I.; Boubekeur, N.; Favre, G.; Pradines, A. RhoB loss induces Rac1dependent mesenchymal cell invasion in lung cells through PP2A inhibition. Oncogene 2016, 35, 1760-1769. [CrossRef]

75. Calvayrac, O.; Mazières, J.; Figarol, S.; Marty-Detraves, C.; Raymond-Letron, I.; Bousquet, E.; Farella, M.; Clermont-Taranchon, E.; Milia, J.; Rouquette, I.; et al. The RAS -related GTP ase RHOB confers resistance to EGFR -tyrosine kinase inhibitors in non-small-cell lung cancer via an AKT -dependent mechanism. EMBO Mol. Med. 2017, 9, 238-250. [CrossRef]

76. Smith, E.M.; Finn, S.G.; Tee, A.R.; Brownei, G.J.; Proud, C.G. The tuberous sclerosis protein TSC2 is not required for the regulation of the mammalian target of rapamycin by amino acids and certain cellular stresses. J. Biol. Chem. 2005, 280, 18717-18727. [CrossRef]

77. Long, X.; Lin, Y.; Ortiz-Vega, S.; Yonezawa, K.; Avruch, J. Rheb binds and regulates the mTOR kinase. Curr. Biol. 2005, 15, 702-713. [CrossRef]

78. Angarola, B.; Ferguson, S.M.; Gruenberg, J.E. Weak membrane interactions allow Rheb to activate mTORC1 signaling without major lysosome enrichment. Mol. Biol. Cell 2019, 30, 2750-2760. [CrossRef]

79. Guri, Y.; Hall, M.N. mTOR signaling confers resistance to targeted cancer drugs. Trends Cancer 2016, 2, 688-697. [CrossRef]

80. Basso, A.D.; Mirza, A.; Liu, G.; Long, B.J.; Bishop, W.R.; Kirschmeier, P. The farnesyl transferase inhibitor (FTI) SCH66336 (lonafarnib) inhibits Rheb farnesylation and mTOR signaling: Role in FTI enhancement of taxane and tamoxifen anti-tumor activity. J. Biol. Chem. 2005, 280, 31101-31108. [CrossRef]

81. Makhov, P.; Sohn, J.A.; Serebriiskii, I.G.; Fazliyeva, R.; Khazak, V.; Boumber, Y.; Uzzo, R.G.; Kolenko, V.M. CRISPR/Cas9 genomewide loss-of-function screening identifies druggable cellular factors involved in sunitinib resistance in renal cell carcinoma. $\mathrm{Br}$. $\mathrm{J}$. Cancer 2020, 123, 1749-1756. [CrossRef] 
82. Yao, X.; Anderson, K.L.; Cleveland, D.W. The microtubule-dependent motor centromere-associated protein E (CENP-E) is an integral component of kinetochore corona fibers that link centromeres to spindle microtubules. J. Cell Biol. 1997, 139, 435-447. [CrossRef]

83. Wood, K.W.; Sakowicz, R.; Goldstein, L.S.B.; Cleveland, D.W. CENP-E is a plus end-directed kinetochore motor required for metaphase chromosome alignment. Cell 1997, 91, 357-366. [CrossRef]

84. Liao, H.; Winkfein, R.J.; Mack, G.; Rattner, J.B.; Yen, T.J. CENP-F is a protein of the nuclear matrix that assembles onto kinetochores at late G2 and is rapidly degraded after mitosis. J. Cell Biol. 1995, 130, 507-518. [CrossRef]

85. Ashar, H.R.; James, L.; Gray, K.; Carr, D.; Black, S.; Armstrong, L.; Bishop, W.R.; Kirschmeier, P. Farnesyl transferase inhibitors block the farnesylation of CENP-E and CENP-F and alter the association of CENP-E with the microtubules. J. Biol. Chem. 2000, 275, 30451-30457. [CrossRef]

86. Hussein, D.; Taylor, S.S. Farnesylation of Cenp-F is required for G2/M progression and degradation after mitosis. J. Cell Sci. 2002, 115, 3403-3414. [CrossRef] [PubMed]

87. Cates, C.A.; Michael, R.L.; Stayrook, K.R.; Harvey, K.A.; Burke, Y.D.; Randall, S.K.; Crowell, P.L.; Crowell, D.N. Prenylation of oncogenic human PTPcaax protein tyrosine phosphatases. Cancer Lett. 1996, 110, 49-55. [CrossRef]

88. Hassan, N.M.M.; Hamada, J.I.; Kameyama, T.; Tada, M.; Nakagawa, K.; Yoshida, S.; Kashiwazaki, H.; Yamazaki, Y.; Suzuki, Y.; Sasaki, A.; et al. Increased expression of the PRL-3 gene in human oral squamous cell carcinoma and dysplasia tissues. Asian Pacific J. Cancer Prev. 2011, 12, 947-951.

89. Wei, M.; Korotkov, K.V.; Blackburn, J.S. Targeting phosphatases of regenerating liver (PRLs) in cancer. Pharmacol. Ther. 2018, 190, 128-138. [CrossRef] [PubMed]

90. Zeng, Q.; Dong, J.-M.; Guo, K.; Li, J.; Tan, H.-X.; Koh, V.; Pallen, C.J.; Manser, E.; Hong, W. PRL-3 and PRL-1 promote cell migration, invasion, and metastasis. Cancer Res. 2003, 63, 2716-2722.

91. Murphy, M.E. The HSP70 family and cancer. Carcinogenesis 2013, 34, 1181-1188. [CrossRef]

92. Karp, J.E.; Lancet, J.E.; Kaufmann, S.H.; End, D.W.; Wright, J.J.; Bol, K.; Horak, I.; Tidwell, M.L.; Liesveld, J.; Kottke, T.J.; et al. Clinical and biologic activity of the famesyltransferase inhibitor R115777 in adults with refractory and relapsed acute leukemias: A phase 1 clinical-laboratory correlative trial. Blood 2001, 97, 3361-3369. [CrossRef] [PubMed]

93. Wolda, S.L.; Glomsets, J.A. Evidence for modification of lamin B by a product of mevalonic acid. J. Biol. Chem. 1988, 263, 5997-6000. [CrossRef]

94. Meta, M.; Yang, S.H.; Bergo, M.O.; Fong, L.G.; Young, S.G. Protein farnesyltransferase inhibitors and progeria. Trends Mol. Med. 2006, 12, 480-487. [CrossRef] [PubMed]

95. Dhillon, S. Lonafarnib: First approval. Drugs 2021, 81, 283-289. [CrossRef] [PubMed]

96. Pan, J.; She, M.; Xu, Z.X.; Sun, L.; Yeung, S.C.J. Farnesyltransferase inhibitors induce DNA damage via reactive oxygen species in human cancer cells. Cancer Res. 2005, 65, 3671-3681. [CrossRef]

97. Liu, A.X.; Cerniglia, G.J.; Bernhard, E.J.; Prendergast, G.C. RhoB is required to mediate apoptosis in neoplastically transformed cells after DNA damage. Proc. Natl. Acad. Sci. USA 2001, 98, 6192-6197. [CrossRef]

98. Chen, J.; Jiang, C.C.; Jin, L.; Zhang, X.D. Regulation of PD-L1: A novel role of pro-survival signalling in cancer. Ann. Oncol. 2016, 27, 409-416. [CrossRef]

99. Ebert, P.J.R.; Cheung, J.; Yang, Y.; McNamara, E.; Hong, R.; Moskalenko, M.; Gould, S.E.; Maecker, H.; Irving, B.A.; Kim, J.M.; et al. MAP kinase inhibition promotes T cell and anti-tumor activity in combination with PD-L1 checkpoint blockade. Immunity 2016, 44, 609-621. [CrossRef]

100. Albert, S.; Riveiro, M.E.; Halimi, C.; Hourseau, M.; Couvelard, A.; Serova, M.; Barry, B.; Raymond, E.; Faivre, S. Focus on the role of the CXCL12/CXCR4 chemokine axis in head and neck squamous cell carcinoma. Head Neck 2013, 35, 1819-1828. [CrossRef]

101. Gualberto, A.; Scholz, C.; Mishra, V.; Janes, M.R.; Kessler, L.; Cutsem, E.; Van Ho, A.L.; Witzig, T. Abstract CT191: Mechanism of action of the farnesyltransferase inhibitor, tipifarnib, and its clinical applications. In Proceedings of the Cancer Research; American Association for Cancer Research (AACR): Philadelphia, PA, USA, 2019; Volume 79, p. CT191.

102. Witzig, T.; Sokol, L.; Jacobsen, E.; Advani, R.; Foss, F.; Mondejar, R.; Piris, M.A.; Bolognese, J.; Burrows, F.; Kessler, L.; et al. The CXCL12/CXCR4 pathway as a potential target of tipifarnib: Preliminary results from an open-label, phase II Study in relapsed or refractory peripheral T-Cell lymphoma. Blood 2017, 130, 2788. [CrossRef] 